\title{
Pengembangan Potensi Desa Tancep dan Pengenalan Batik Khas Tancep, Ngawen, Kabupaten Gunungkidul, Yogyakarta
}

\author{
Riantama Meidiarto Yustus Makuan, Adi Wijaya, Katharina Kintan Anggaretha, Adelheid Lorensa Anggie Venantin, Alessandro Ardi \\ Setyanto, Komang Aditya Tri Wardana, Wendy Winata, Cornelius Exel Richardo Lenggoe, Chyntia Limas, Hendra Gunawan Sianturi, Ika \\ Murti Kristiyani. \\ Universitas Atma Jaya, Jl. Babarsari No.44, Janti, Caturtunggal, Kec. Depok, Kabupaten Sleman, Daerah Istimewa Yogyakarta \\ 55281 \\ Email: $\underline{\text { ika.murti@uajy.ac.id }}$
}

Received: June 15, 2021; Revised: -; Accepted for Publication: March 15, 2023; Published: March 28, 2023

\begin{abstract}
Natural resources are something that become the advantages of Tancep Village. Big amounts of natural dyes are available for batik in Tancep Village. Besides that, bamboo plant enlivens the atmosphere in Tancep Village. Natural dyes have been managed well, but not the bamboo plant. Batik of Tancep is a potential creation. However, it is not well-known in general public. Therefore, the authors want to develop the bamboo plat potential and introducing the Batik of Tancep to wide public. Hope thus can increase the sale value of bamboo plant and increase the economy of Tancep Village.
\end{abstract}

Key words-Tancep Village, Bamboo Plant, Village Potential

Abstrak - Sumber daya alam merupakan suatu hal yang menjadi kelebihan di Desa Tancep. Pewarna alami untuk batik tersedia dalam jumlah banyak di daerah Desa Tancep. Selain itu, tanaman bambu juga meramaikan suasana di daerah Desa Tancep. Pewarna alami batik sudah dikelola dengan baik, sedangkan untuk tanaman bambu tersebut masih belum dikelola dengan baik. Batik Tancep sendiri merupakan karya yang sungguh berpotensi, namun masih belum dikenal baik oleh masyarakat luar, sehingga penulis ingin mengembangkan potensi kelola tanaman bambu dan memperkenalkan lebih luas Batik Tancep kepada masyarakat luar. Harapannya dengan memperkenalkan Batik Tancep dan meningkatkan nilai jual dari tanaman bambu dapat perlahan meningkatkan ekonomi dari Desa Tancep.

Kata Kunci-Batik Tancep, Tanaman bambu, Potensi desa

\section{Pendahuluan}

Setiap hal memiliki potensi berkembangnya masingmasing. Perbedaan ditemukan dimana-mana dan dianggap sebagai keunikan masing-masing, begitu pula dengan desa. Desa dengan kuantitasnya yang begitu banyak tentu memiliki perbedaan dan keunikannya masing-masing pula. Perbedaan dalam kondisi tertentu dapat dianggap buruk, namun bila dilihat dari sudut pandang yang benar dapat menjadi suatu hal yang luar biasa. Perbedaan dapat menjadi spesialitas dan menjadi hal yang unik. Spesialitas inilah yang dapat menjadi salah satu potensi berkembangnya suatu desa.

Setiap desa memiliki spesialitas masing-masing dan untuk Desa Tancep, hal tersebut adalah karya budayanya, yaitu Batik Tancep [1]. Batik Tancep secara turun temurun sudah diajarkan kepada penduduk Desa Tancep. Banyak penduduk yang berprofesi sebagai pembatik, karena Batik Tacep sendiri selama ini masih dibuat secara manual [2]. Pemasaran Batik Tancep selama ini secara garis besar ditemui pada Kota Solo dan Yogyakarta, namun melihat potensi Batik Tancep yang besar, akhirnya sempat dilakukan impor ke Eropa [3]. Kesempatan-kesempatan seperti itulah yang perlu dikembangkan lagi, oleh karena itu diperlukan pengenalan bertahap mulai dari masyarakat Indonesia sendiri, kemudian perlahan akan dikenal oleh masyarakat luar. Sehingga akan meningkatkan probabilitas pemesanan dan meningkatkan ekonomi Desa Tancep.

Cikal bakal spesialitas lain penulis temui pula pada sumber daya alam yang terdapat pada Desa Tancep, yaitu tanaman bambu. Tumbuhnya tanamanan bambu secara alami di Desa Tancep adalah potensi yang terpendam. Selama ini tanaman bambu belum dimanfaatkan dengan baik, padahal dapat ditingkatkan nilai jualnya bila dikelola dengan baik.

Oleh karena hal-hal tersebut, untuk menambah dan mengembangkan spesialitas dari Desa Tancep, Kecamatan Ngawen, Kabupaten Gunungkidul, maka penulis ingin membantu segenap Desa Tancep untuk lebih maju lagi di bidang ekonomi. Setelah melihat dan menyadari potensi yang ada di Desa Tancep, penulis menjadi bersemangat untuk mengenalkan secara perlahan mengenai cara pengelolaan bambu kepada penduduk Desa Tancep dan mengenalkan Batik Tancep kepada masyarakat luar.

\section{Metode Pengabdian}

\section{A. Waktu Pelaksanaan}

Kegiatan dilaksanakan secara daring dari tanggal 1 April 2021 sampai 31 Mei 2021. Data-data dikumpulkan melalui media online.

\section{B. Identifikasi Masalah}

Melihat kondisi dari Desa Tancep, identifikasi masalah dilakukan guna menemukan permasalahan yang sedang dihadapi oleh masyarakat Desa Tancep. Proses identifikasi masalah ini mendapatkan input dari informasi-informasi yang tersedia di beberapa website, sedangkan output dari proses ini adalah permasalahan terkait pemasaran Batik Tancep yang masih sulit penyebarannya dan adanya sumber daya alam yang masih belum dimanfaatkan secara maksimal, yaitu tanaman bambu.

\section{Pengumpulan Data}

Berbagai data yang telah diperoleh melalui sumbersumber yang ditemukan dan dicari melalui internet merupakan data yang relevan dengan topik yang ingin 
disampaikan pada makalah ini. Berikut merupakan cara-cara penulis dalam pengambilan data:

1. Informasi mengenai kondisi, kelebihan, dan potensi desa didapatkan melalui website resmi desa, website resmi kabupaten, dan juga hasil observasi melalui artikel-artikel yang terkait dengan desa tersebut.

2. Informasi mengenai potensi desa yang ditemukan di media dirangkum dengan bahasa sendiri secara logis dan jelas.

3. Data mengenai Batik Tancep serta cara memaksimalkan potensi desa Batik Tancep diperolah dari artikel-artikel di internet.

\section{Metode Penelitian}

Metode yang digunakan dalam penelitian ini adalah metode analisis deskriptif. Dari identifikasi masalah dan pengumpulan data dengan studi pustaka, penulis mendapatkan data yang kemudian dideskripsikan dengan detail dan rinci.

\section{HASIL DAN PEMBAHASAN}

Potensi di Desa Tancep meliputi tanaman bambu sebagai salah satu kekayaan alam desa dan Batik Khas Desa Tancep.

\section{A. Bambu}

Desa Tancep yang mana sebagian besar daerahnya masih berupa tanaman merupakan salah satu kelebihan menonjol yang bisa dilihat. Salah satu kekayaan alam di sekitar Desa Tancep adalah tanaman bambu. Hal ini tentunya merupakan potensi yang dapat digali. Banyaknya masyarakat Desa Tancep yang menjadi buruh harian lepas, ibu rumah tangga, dan belum memiliki profesi, dapat dijadikan pengrajin. Hal ini memiliki tujuan didapatkannya sektor bisnis baru berupa pengolahan bambu yang selama ini masih belum ditakar tinggi nilai ekonominya. Dengan dilakukannya pengolahan bambu, maka nilai ekonomi dari tanaman bambu yang selama ini tidak dipakai akan menjadi hal positif bagi perkembangan Desa Tancep [4].

\section{Cara Pengawetan Bambu}

a. Pengawetan Tradisional

Pengawetan dengan cara tradisional ini masih menggunakan bahan-bahan alami dan sudah dilakukan oleh masyarakat secara turun temurun yang ber tujuan untuk meningkatkan masa pakai bambu. Berikut ini adalah cara pengawetan bambu, diantaranya adalah:

- Pengendalian waktu tebang

- Perendaman bambu

- Pengasapan bambu

- Pencelupan dengan kapur

- Pemanggangan / pembakaran

b. Pengawetan Modern

Pengawetan dengan cara modern adalah pengawetan yang menggunakan input bahan-bahan kimia. Efisiensi pengawetan kimia terhadap peningkatan umur bambu dipengaruhi oleh struktur umur bambu itu sendiri. Bahanbahan yang digunakan adalah Zinc Chloride / Copper
Sulphate, Sodium Penta ChloroPhenate, Copper Chrome Arsenic dan Ammoniacal Copper Arsenate, Copper Cromium Boron, dan Karosete [5]

\section{Tips Merawat Bambu}

Bambu yang sudah melalui proses pengawetan, tidak dapat dibiarkan begitu saja tanpa adanya proses selanjutnya, bambu yang tidak dirawat dan terus menerus terpapar oleh kelembaban dan terik sinar matahari, maka bambu tersebut akan lapuk dan akhirnya rusak. Cara yang paling mudah untuk merawat bambu adalah memberikan lapisan pelindung cat coating dan dianjurkan sedikitnya 1 tahun sekali untuk memberikan lapisan coating ini [6].

\section{Hasil Kerajinan Bambu}

a. Kipas

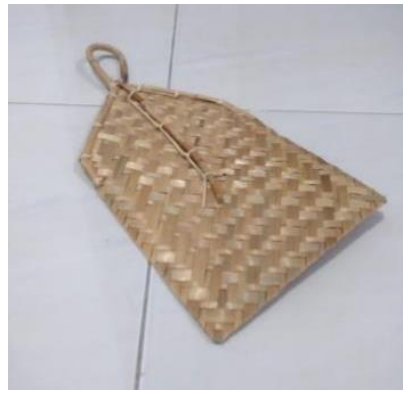

Gambar 1. Kipas

b. Keranjang

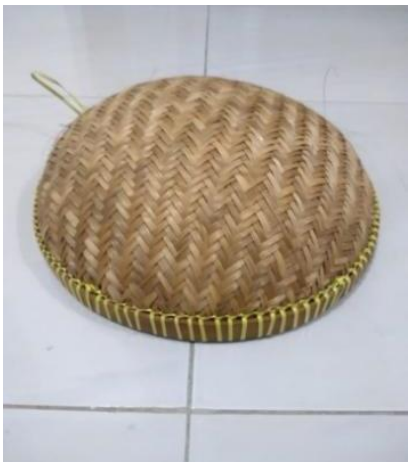

Gambar 2. Keranjang

c. Meja

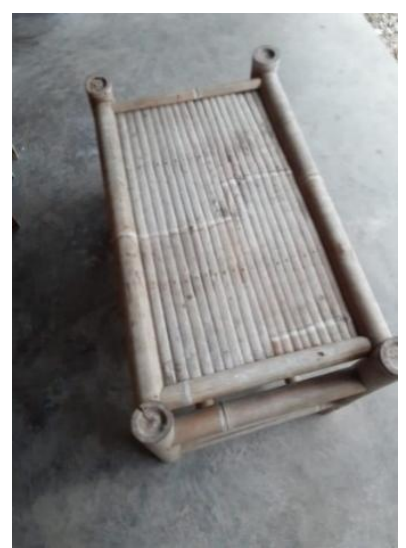




\section{Gambar 3. Meja}

\section{d. Rumah lampu}

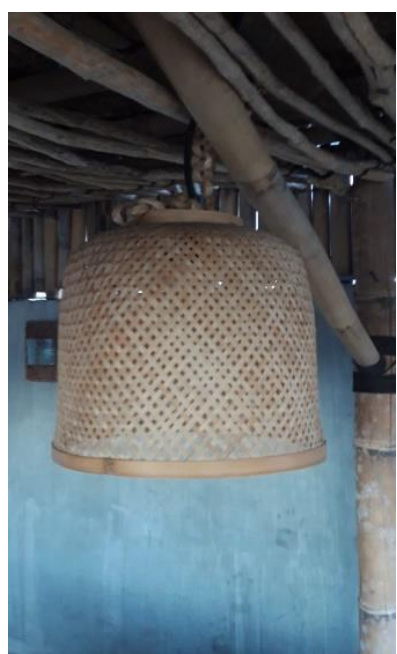

Gambar 4. Rumah Lampu

e. Tirai

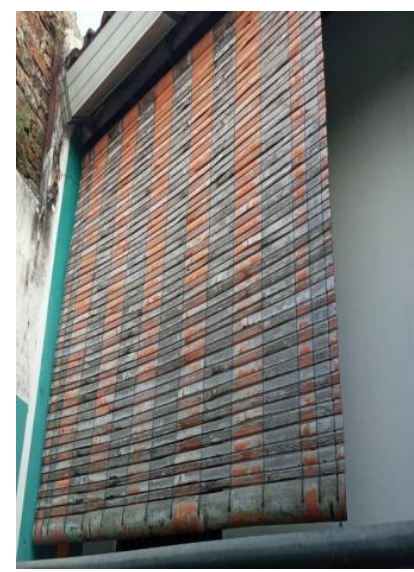

Gambar 5. Tirai

\section{f. Caping}

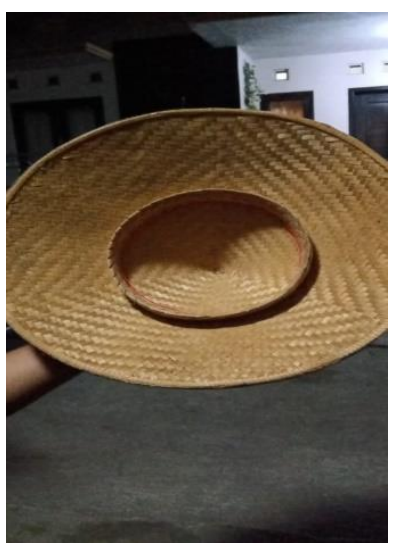

Gambar 6. Caping

\section{B. Batik}

Batik merupakan warisan budaya dengan berbagai makna yang terkandung meliputi ciri khas setiap daerah, filosofi, serta makna yang dimiliki. Oleh karena itu batik memiliki daya tarik sendiri bagi wisatawan mancanegara maupun lokal. DIY identik dengan pengrajin batik dan salah satu daerah pengrajin batik adalah Desa Tancep, Kecamatan Ngawen, Gunungkidul. Ciri khas yang dimiliki oleh batik di Desa Tancep adalah warna yang didominasi oleh biru keunguan, hijau, dan cokelat. Dengan motif perpaduan antara daerah Solo dan Yogyakarta karena berada diantara kedua daerah tersebut.

\section{Keunikan Batik Desa Tancep}

Ada hal unik dari pengrajin batik di Desa Tancep ialah warna yang digunakan berasal dari bahan alami yaitu tumbuh-tumbuhan yang ada di sekitar. Dengan memanfaatkan bahan alami sebagai pewarna hal tersebut tidak mencemari lingkungan dan tidak memerlukan biaya yang mahal. Cara untuk menyiasati pewarna alami adalah dengan menanam tumbuhan di pekarangan rumah seperti tumbuhan soga yang dapat menghasilkan warna cokelat, pohon tegeran menghasilkan warna hijau, warna kuning dihasilkan oleh pohon nangka dan lain sebagainya. Dampak yang langsung dirasakan oleh masyarakat sekitar adalah lingkungan yang menjadi lebih asri dan hijau, mengingat bahwa daerah Gunungkidul merupakan daerah tanah kapur dan tandus [1].

\section{Motif Batik Desa Tancep}

Motif yang identik dimiliki oleh Desa Tancep terdiri dari motif babon angrem, buah naga, jejeran perahu baron, walang sinanding jati, karang dan rumput laut, walang coletan, walang kencono jati, udang, dan bledak. Berikut ini penjelasan tentang beberapa jenis Batik Tancep:

a. Batik Jejeran Perahu Baron

Melambangkan kehidupan yang seiring dan berirama serta menggambarkan kehidupan masyarakat yang penuh makna dan saling beriringan di tengah perbedaan yang ada.

b. Batik Buah Naga

Memiliki ciri-ciri berwarna cerah dan memberi kesan ceria. Batik Buah Naga ini memiliki tujuan untuk menyampaikan kesan individual, seni kolektif, kreatif, dan keindahan.

c. Batik Walang Coletan

Memiliki arti kegembiraan layaknya seekor capung yang terbang bebas. Batik ini juga menggambarkan kehidupan masyarakat yang menjalankan hidup penuh dengan kegembiraan.

d. Batik Bledak

Memiliki arti filosofi Sido Mukti yang berarti gembira. Motif ini biasanya digunakan untuk menggendong bayi dan melambangkan ketika menggendong bayi menggunakan motif ini akan merasakan kegembiraan dan ketenangan.

e. Batik Babon Anggrem 
Terinspirasi dari ayam betina yang sedang mengerami telur-telurnya. Batik ini memiliki arti seorang ibu yang sedang mengandung diharapkan memiliki sifat baik agar nantinya anak yang dilahirkan akan mewarisi sifat tersebut [7].

\section{Langkah-Langkah Membuat Batik}

Selain variasi dari Batik Tancep, batik tulis juga diperkenalkan secara singkat dan dijelaskan pula cara untuk membuatnya. Berikut adalah langkah-langkah untuk membuat batik tulis:

a. Menyiapkan beberapa alat dan bahan.

Hal yang perlu disiapkan untuk membuat batik tulis, yaitu:

- Kain Mori/kain yang terbuat dari sutra

- Canting

- Gawangan

- Malam (lilin untuk membatik)

- Wajan, panci, dan kompor kecil

- Pewarna (sesuai selera)

- Pensil

- Kuas (opsional)

b. Tentukan motif batik yang ingin dibuat, kita juga bisa mencoba meniru motif batik yang sudah ada.

c. Gambar motif batik pada kain mori dengan pensil.

d. Panaskan malam dengan wajan di atas kompor, lalu ambil sedikit menggunakan canting, dan lukiskan di atas motif yang kita buat.

e. Menutup kain yang kosong, atau terlihat polos dengan menggunakan canting atau kuas, hal ini dilakukan agar kain tetap polos atau kosong.

f. Keringkan kain tersebut di atas gawangan.

g. Jika memiliki pola lainnya, lakukan pembatikan kembali dengan menggunakan canting pada pola tertentu, dan jemur kembali.

h. Setelah pembatikan kedua selesai, lakukan pewarnaan dengan mencelupkan kain pada pewarna kedua.

i. Langkah ke 6 dan ke 7 akan di ulang terus selama kita masih memiliki pola yang berbeda dengan yang kita buat sebelumnya.

j. Langkah terakhir, rebus kain di dalam panci yang dijerang di atas kompor agar lapisan malam bisa hilang. Lalu jemur kain hingga kering, dan kain siap digunakan [8].

4. Cara Merawat Batik

Batik yang baik tentunya memerlukan perawatan yang baik pula. Berikut beberapa cara merawat batik, antara lain:

a. Mencuci batik tidak dengan mesin melainkan dengan tangan

Cara untuk mencuci batik dengan baik adalah menggunakan tangan akan tetapi tidak memerlukan sikat agar warna dari batik itu sendiri tidak mengalami luntur atau pudar. Cukup merendam batik dengan waktu 15 hingga 30 menit. Saat menjemur, hindari sinar matahari secara langsung karena dapat menyebabkan warna kain cepat rusak atau pudar. Mencuci batik dengan mesin pencuci baju, hal ini yang dapat merusak kuali tas dari batik itu sendiri dengan cara memutar dan mengaduk yang dapat berakibat serat kain dari batik tersebut dapat tertarik dan menyebabkan kain nya berkerut.

b. Saat mencuci tidak disarankan dengan deterjen Kandungan kimiawi pada deterjen dapat merusak dan mengurangi kuali tas pada kain batik. Hal opsional yang dapat dilakukan adalah menggunakan biji lerak untuk dijadikan sebagai deterjen tradisional yang bijinya mengandung saponin dan kandungan alkaloid yang menghasilkan busa yang dapat membersihkan noda, minyak, dan kotoran pada kain batik.

c. Tidak disarankan menggunakan pewangi baju Dengan menggunakan pewangi baju maka akan mengurangi kuali tas dari kain batik sendiri karena senyawa kimia dalam pewangi jika dipaparkan secara langsung dapat membuat batik itu sendiri memudar. Jika ingin menyemprotkan pewangi ke kain bat ik sebaiknya menutupi permukaan kain dengan tisu atau koran lalu semprotkan cairan pewangi di atas tisu atau koran tersebut.

d. Menyetrika kain batik

Ketika ingin menyetrika kain batik baik dengan setrika listrik atau uap, disarankan agar melapisi kain batik dengan kain di atas permukaan batik. Hal tersebut dilakukan untuk menghindari kain batik dengan panas yang berlebihan dari setrika yang digunakan. Bisa juga dengan cara membalikkan kain batik sehingga yang cukup disetrika hanya bagian dalam saja.

e. Menyimpan batik agar tidak dimakan ngengat

Banyak pengguna bat ik yang menyimpan batik di lemari dengan diberi kapur barus, padahal hal itu dapat menyebabkan kerusakan pada batik sendiri. Cara lain agar batik tidak dimakan ngengat dengan tetap menjaga kuali tas kain batik sendiri dengan memberi sedikit merica lalu dibungkus dengan tisu dan diletakkan disudut lemari tempat penyimpanan batik.

f. Menyimpan batik dengan perlakuan khusus

Batik harus disimpan dengan perlakuan yang khusus. Cara menyimpan batik yang baik dengan menyimpan batik di lemari dengan suhu yang kering. Jika bat ik disimpan di area yang lembab, maka akan menarik binatang seperti ngengat untuk menggerogoti sehingga menyebabkan batik tersebut berlubang. Cara lain untuk menyimpan batik, menyimpannya dengan dilapisi kain ataupun kertas agar tetap menjaga kuali tas dari batik itu sendiri [9].

\section{Respon Pemerintah}

Bupati Gunungkidul merespon positif industri kreatif yang dimiliki oleh masyarakat karena hal ini beriringan dengan proses pembangunan pariwisata di sekitar. Respon yang diberikan Pemerintah Gunungkidul dengan melakukan penanaman 10.000 pohon khususnya di sentra kerajinan batik 
yang tersebar di daerah Gunungkidul salah satunya Desa Tancep, Kecamatan Ngawen. Program yang dicanangkan Pemerintah Gunungkidul bekerja sama dengan Lembaga Lions Club Puspita Mataram yaitu Lembaga yang bergerak di bidang lingkungan hidup dan kesejahteraan masyarakat dengan memberikan 10.000 bibit pohon mangga, manggis, jambu, buah naga, nangka dan indigofera.

Diharapkan makalah ini dapat memberikan informasi tentang Batik Tancep yang selama ini belum dikenal oleh masyarakat luas, juga menambah wawasan bagi orang-orang yang membacanya. Bagi masyarakat desa, makalah ini adalah salah satu cara memperkenalkan produk yang mereka buat secara tidak langsung maupun untuk warga desa pelajari agar dapat memperkenalkan Batik Tancep secara langsung. Bagi masyarakat di luar desa, makalah ini merupakan jembatan untuk mengenal batik tulis, terutama Batik Tancep ke tahap yang lebih dalam lagi. Oleh karena banyaknya informasi yang disampaikan makalah ini, harapannya dapat menjangkau banyak orang dan meningkatkan rasa ingin tahu orang-orang luar juga tentunya meningkatkan perekonomian Desa Tancep terutama dari penjualan Batik Tancep [10].

\section{KESIMPULAN}

Ada potensi-potensi desa yang dapat dioptimalkan, antara lain bambu dan batik. Masyarakat dapat memanfaatkan tanaman bambu menjadi kerajinan yang dapat digunakan pada kehidupan sehari-hari. Kerajinan tersebut seperti kipas, meja, lampu, tirai, keranjang, caping, dan sebagainya. Masyarakat juga dapat mengembangkan potensi batik khas desa melalui tips dalam makalah ini, antara lain melakukan perawatan batik khas desa agar motif yang telah dibentuk tidak rusak atau memudar. Penulis juga mencantumkan cara membuat batik tulis. Selain lebih memahami potensi desa masing-masing, masyarakat juga dapat mempraktikan sendiri cara membuat batik serta cara merawat kain batik yang dimiliki.

\section{UCAPAN TERIMAKASIH}

Penulis mengucapkan terima kasih kepada seluruh pihak yang telah mendukung selama proses penulisan artikel ini.

\section{DAFTAR PUSTAKA}

[1] Hari, "Batik Tulis Tancep, Batik Khas dari Gunung Kidul," Article, Apr. 2015

[2] Anonim, "Pelatihan Kerajinan Batik," Article, 2018. https://www.tancep-ngawen.desa.id/first/artikel/108-PELATIHANKERAJINAN-BATIK.

[3] Anonim, "Batik Tancep Menembus Pasar Eropa," Article, 2012. http://gdhe.web.id/batik-tancep-menembus-pasar-eropa/.

[4] D. A. Kurniawati, "Bambu: Pengertian, Morfologi, dan Potensi," Article, 2019. https://foresteract.com/bambu/.

[5] Anonim, "Mari Mengenal Proses Pengawetan Bambu dari A sampai Z," 2021. https://arafuru.com/sipil/mari-mengenal-proses-pengawetanbambu-dari-a-sampai-z.html.

[6] Anonim, "Cara Merawat Produk / Bangunan Bambu," Article, 2021. https://sahabatbambu.com/Perawatan.html.

[7] R. Swastika, "9 Motif Batik Tancep Gunungkidul yang Indah Bernilai Tinggi," Article, 2019.

[8] A. H. Ikramah, "Cara Membuat Batik Tulis Sederhana untuk Tugas Sekolah," Article, 2020. https://portaljember.pikiranrakyat.com/pendidikan/pr-16794696/cara-membuat-batik-tulissederhana-untuk-tugas-sekolah.

[9] Anonim, "7 Cara Merawat dan Menyimpan Batik," Article, 2020. https://www.infobatik.com/7-cara-merawat-dan-menyimpan-batiktulis/.

[10]M. Muryanti, "Menuju Kewirausahaan Sosial di Desa melalui Badan Usaha Milik Desa," vol. 8, no. 1, pp. 170-181, 2020, doi: 10.33019/society.v8i1.161.

\section{PENULIS}

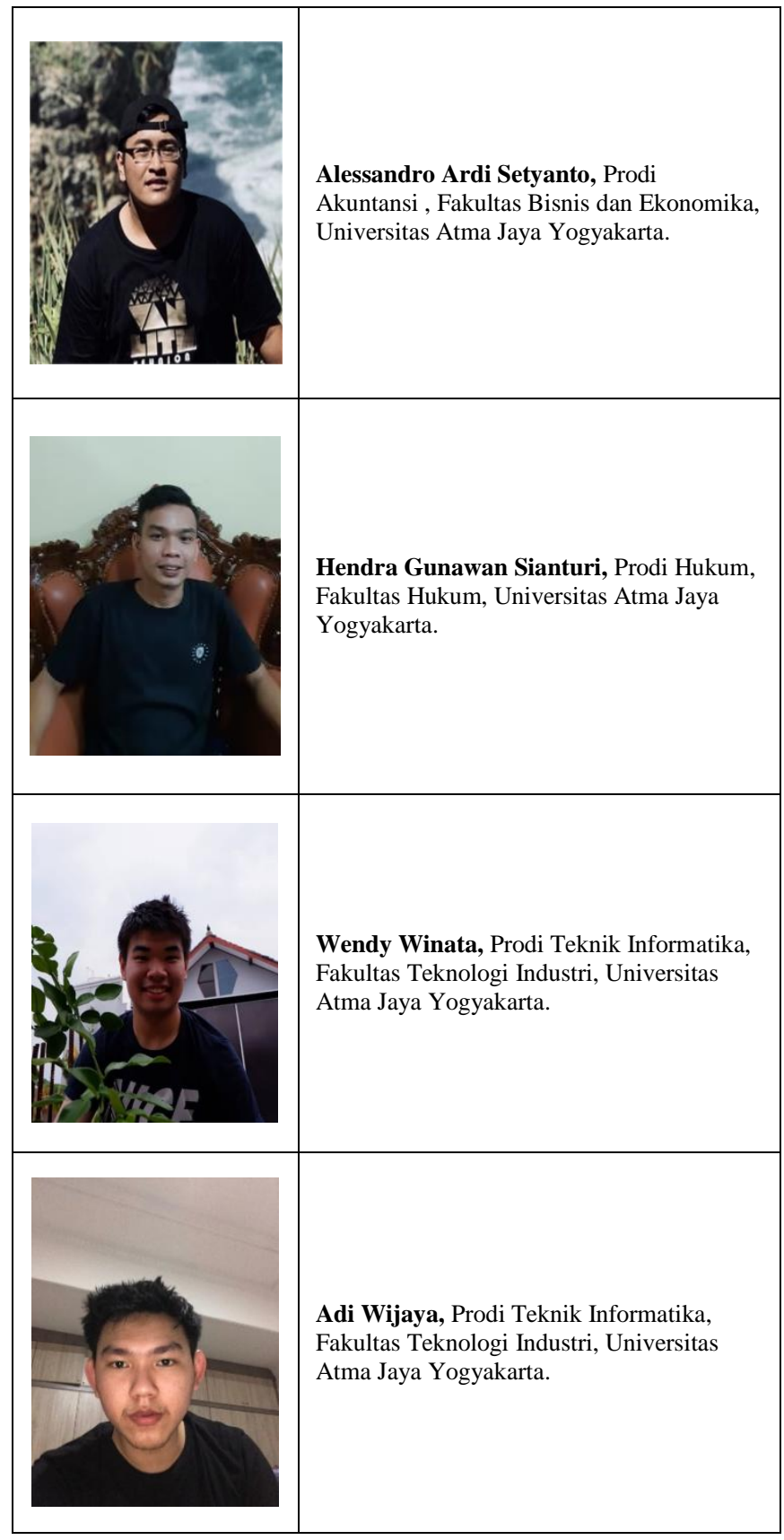


Pengembangan Potensi Desa Tancep dan Pengenalan Batik Khas Tancep, Ngawen, Kabupaten Gunungkidul, Yogyakarta

\begin{tabular}{l|l|} 
& $\begin{array}{l}\text { Riantama Meidiarto Yustus Mukuan, } \\
\text { Sistem Informasi, Fakultas Teknologi } \\
\text { Industri, Universitas Atma Jaya Yogyakarta. }\end{array}$ \\
\hline Komang Aditya Tri Wardana, Teknik \\
Industri, Fakultas Teknologi Industri, \\
Universitas Atma Jaya Yogyakarta.
\end{tabular}

\begin{tabular}{|l|l|}
\hline Chyntia Limas, Prodi Teknik Sipil, \\
Fakultas Teknik, Universitas Atma Jaya \\
Yogyakarta.
\end{tabular}

